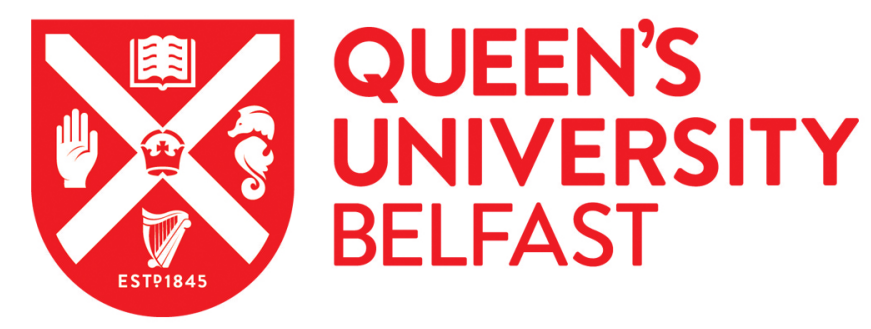

\title{
A novel membrane-disruptive antimicrobial peptide from frog skin secretion against cystic fibrosis isolates and evaluation of anti-MRSA effect using Galleria mellonella model
}

Yuan, Y., Zai, Y., Xi, X., Ma, C., Wang, L., Zhou, M., Shaw, C., \& Chen, T. (2019). A novel membrane-disruptive antimicrobial peptide from frog skin secretion against cystic fibrosis isolates and evaluation of anti-MRSA effect using Galleria mellonella model. BIOCHIMICA ET BIOPHYSICA ACTA-GENERAL SUBJECTS, 1863(5), 849856. https://doi.org/10.1016/j.bbagen.2019.02.013

\section{Published in:}

BIOCHIMICA ET BIOPHYSICA ACTA-GENERAL SUBJECTS

\section{Document Version:}

Peer reviewed version

Queen's University Belfast - Research Portal:

Link to publication record in Queen's University Belfast Research Portal

\author{
Publisher rights \\ Copyright 2019 Elsevier. \\ This manuscript is distributed under a Creative Commons Attribution-NonCommercial-NoDerivs License \\ (https://creativecommons.org/licenses/by-nc-nd/4.0/), which permits distribution and reproduction for non-commercial purposes, provided the \\ author and source are cited.

\section{General rights} \\ Copyright for the publications made accessible via the Queen's University Belfast Research Portal is retained by the author(s) and / or other \\ copyright owners and it is a condition of accessing these publications that users recognise and abide by the legal requirements associated \\ with these rights.
}

\section{Take down policy}

The Research Portal is Queen's institutional repository that provides access to Queen's research output. Every effort has been made to ensure that content in the Research Portal does not infringe any person's rights, or applicable UK laws. If you discover content in the Research Portal that you believe breaches copyright or violates any law, please contact openaccess@qub.ac.uk. 


\title{
A Novel Membrane-Disruptive Antimicrobial Peptide from Frog Skin Secretion against Cystic Fibrosis isolates and Evaluation of Anti-MRSA Effect Using Galleria mellonella Model
}

\section{Yipeng Yuan', Yu Zai ${ }^{\ddagger}$, Xinping Xi*, Chengbang Ma, Lei Wang, Mei Zhou, Chris Shaw and Tianbao Chen}

Natural Drug Discovery Group, School of Pharmacy, Queen's University Belfast, Belfast, Northern Ireland, UK, BT9 7BL

${ }^{1}$ Authors contribute equally to this work.

*Corresponding author. Email: $\underline{x . x i @ q u b . a c . u k}$

\begin{abstract}
Antimicrobial peptides from amphibian skin secretion are a promising source for the development of alternative antibiotics against the urgent antibiotic resistance. Methicillinresistant S. aureus (MRSA) has been found to persist in both early and late disease course of cystic fibrosis (CF). Japonicin-2LF was isolated from the skin secretion of Fujian Large-headed Frog (Limnonectes fujianensis) via the combination of cDNA cloning and MS/MS sequencing. The antimicrobial and anti-biofilm activities of japonicin-2LF were evaluated using both reference and clinic isolated strains. The permeability of the cell membrane treated by the peptide was revealed by fluorescent staining. The cytotoxicity was examined by haemolysis, MTT and LDH assays. Wax moth larvae (Galleria mellonella) infection model was applied to assess the efficacy of japonicin-2LF against the reference and clinic MRSA isolates in vivo. Japonicin-2LF exhibited potent antimicrobial activity, particularly against Gram-positive bacteria Staphylococcus aureus and MRSA, killing the bacteria via membrane permeabilisation. Additionally, Japonicin-2LF demonstrated the inhibition and eradication of biofilms, particularly against the biofilm of MRSA by eradicating the biofilm matrix as well as
\end{abstract}


killing all the sessile bacteria. In the in vivo assay, Japonicin-2LF significantly decreased the mortality of MRSA acute infected larvae. In conclusion, it is a novel antimicrobial peptide discovered from the skin secretion of Limnonectes fujianensis, and particularly effective against both planktonic and sessile MRSA. The further in vivo study suggests that Japonicin2LF could be a potential drug candidate to control the MRSA infection in cystic fibrosis patients.

Keywords: Cystic fibrosis; Methicillin-resistant Staphylococcus aureus; Biofilm; Antimicrobial peptides; Wax moth larvae.

\section{Introduction}

Cystic Fibrosis (CF) is an autosomal recessive, fatal and chronic hereditary exocrine gland disease which results in thickening lung secretions caused by the defect of chloride ion channel of the patient's epithelial cell [1]. The high amount and viscosity of the lung secretions make the lung become a perfect breeding ground for bacteria. New-generation antibiotics treatment may eradicate the bacterial infection and improve the patients' lung condition, but continuous antibiotic treatment makes bacteria develop resistance to drugs and eventually cause the failure of major commercial antibiotics [2-4]. Methicillin-resistant Staphylococcus aureus (MRSA) is one of the severe antibiotic-resistant Gram-positive bacteria, imposing more difficulties on treating CF patients [5-7]. MRSA infection elevated shockingly to the $25 \%$ of the CF population in the USA in 2015 [8], and higher risk factors for MRSA infection CF patients were identified afterwards [9]. Fortunately, it has been found that the conjoint use of antimicrobial peptides (AMPs) and ivacaftor augments the antimicrobial therapeutics in treating CF patients' respiratory infection [10]. 
Because of the serious antibiotic-resistant situation around the world, AMPs, with a unique bactericidal mechanism, are a promising molecule pool for developing a new treatment for bacterial infections $[11,12]$. Among massive AMPs discovered at present, those derived from amphibian skin secretion have demonstrated remarkable biological efficacy and potential clinical application [13]. Generally, they are potent against different kinds of microorganisms with a wide-broad antimicrobial spectrum [14], targeting on the phospholipid bilayer of bacteria and resulting in rapid membrane permeabilisation, which effectively kills antibiotic resistance bacteria without the further possibility for developing new resistance $[15,16]$.

In this study, a novel antimicrobial peptide with 20 amino acids was discovered from the skin secretion of Limnonectes fujianensis by molecular cloning and MS/MS sequencing. The peptide was synthesised by solid phase peptide synthesis for further biofunction study. The synthetic replicates were subjected to different bacterial strains, both reference and CF clinical isolated strains. The interaction between japonicin-2LF and bacteria cells membrane was monitored by fluorescence staining. Additionally, the biofilm eradication activity on MRSA was also investigated. Afterwards, the wax moth larvae were employed to study the anti-MRSA effect of japonicin-2LF by wax moth larvae model.

\section{Materials and Methods}

\subsection{Acquisition of Skin Secretion of Fujian Large-headed Frog, Limnonectes fujianensis}

Three specimens of adult Fujian Large-headed Frog, L. fujianensis (snout-to-vent length 4-7 $\mathrm{cm}$ ) were captured during expeditions in Fujian province, China. The skin secretion of the frogs was acquitted by mild transdermal electrical stimulation through the dorsal skin [17], and after which, the frogs were released. Harvested secretion was dissolved in distilled deionised water 
$\left(\mathrm{ddH}_{2} \mathrm{O}\right)$ and frozen by liquid nitrogen prior to lyophilisation. The lyophilised skin secretion was preserved in $-20^{\circ} \mathrm{C}$ before analysis.

\subsection{Identification of Precursor-Encoding cDNA from the Skin Secretion}

The prepropeptide encoding cDNA from the lyophilised skin secretion was achieved as described previously [18]. The degenerate primer was 5'CCCRAAKATGTTSACCTYRAAGAAA-3' $(\mathrm{R}=\mathrm{A} / \mathrm{G} ; \mathrm{K}=\mathrm{T} / \mathrm{G} ; \mathrm{S}=\mathrm{C} / \mathrm{G} ; \mathrm{Y}=\mathrm{C} / \mathrm{T})$, designed from a highly-conserved domain within the 5'-untranslated regions of closely-related Rana species. The RACE products were cloned by pGEMT easy vector system (Promega, UK) and sequenced by ABI 3100 automated capillary sequencer (Applied Biosystems, Foster City, CA, USA). Sequence analysis was carried out with the NCBI-BLAST (last accessed 14 June 2018). The nucleotide sequence of japonicin-2LF has been deposited in the GenBank database under accession number MH752764.

\subsection{Isolation of Japonicin-2LF from Skin Secretion}

The isolation and identification of mature peptide in the skin secretion using RP-HPLC and LC-MS analysis were performed as the previous study [19]. The MS/MS spectrum was analysed by Thermo Scientific Proteome Discoverer 1.0 software, via Sequest algorithm against the self-defined fasta database (Thermo Fisher Scientific, San Jose, CA, USA).

\subsection{Solid Phase Peptide Synthesis}

The peptide was chemically-synthesised using the automatic Tribute peptide synthesiser as previously described [20]. In order to form the disulphide bond, a final concentration of $0.01 \%$ hydrogen peroxide (Sigma-Aldrich, UK) was added to peptide solution with gentle stirring, standing open to atmosphere until the reaction was completed. The purification of japonicin2LF was achieved by RP-HPLC and MALDI-TOF mass spectrometry following lyophilisation. 


\subsection{Secondary Structure Analysis of Synthetic Peptide}

The secondary structure was determined by using a JASCO J815 circular dichroism spectrometer (JASCO Inc., USA). $100 \mu \mathrm{M}$ of each peptide sample was prepared in the aqueous $10 \mathrm{mM}$ ammonium acetate $\left(\mathrm{NH}_{4} \mathrm{Ac}\right.$; Sigma-Aldrich, UK) buffer, and the membrane-mimic solution 50/50 (v/v) 2,2,2-trifluoroethanol (TFE; Sigma-Aldrich, UK)/10 mM NH4Ac and 50 $\mathrm{mM}$ SDS/10 mM NH4Ac, respectively, loading in a 1-mm thickness quartz cuvette. Each sample was analysed at room temperature with the following parameters: scan range of 190$250 \mathrm{~nm}$, scanning speed of $100 \mathrm{~nm} / \mathrm{min}, 1 \mathrm{~nm}$ bandwidth, and $0.5 \mathrm{~nm}$ data pitch. The spectra were obtained by averaging data from three scans.

\subsection{Determination of Minimal Inhibitory Concentration (MIC) and Minimal Bactericidal Concentration (MBC)}

The MIC and MBC of japonicin-2LF were determined against different microorganisms by broth dilution method [20] with minor modifications. The reference strains including Staphylococcus aureus (NCTC 10788), Escherichia coli (NCTC 10418), Candida albicans (NCYC 1467), methicillin-resistant Staphylococcus aureus (MRSA, NCTC 12493) and Pseudomonas aeruginosa (ATCC 27853), and the clinical isolates, MRSA (B038 V1S1 A), MRSA (B042 V2E1 A) and P. aeruginosa (B004 V2S2 B) from CF patients that are the courtesy of Prof. Michael Tunney (CF and airways research group, Queen's University Belfast, UK), were employed in this study.

\subsection{Induction of Resistance to Japonicin-2LF}

The induction of resistance to Japonicin-2LF was performed as previous study [15], with three MRSA strains. In brief, MRSA were inoculated in the Mueller-Hinton broth (MHB) containing Japonicin-2LF at the concentration of the respective $1 / 2$ MICs, with an inoculum ratio as 1:10. 
After 15 cycles, bacteria were subjected to MIC assay as described above in a peptide-free MHB.

\subsection{Inactivation of Japonicin-2LF on MRSA by $P$. aeruginosa supernatant}

P. aeruginosa supernatant was prepared as previous method [21]. $50 \mu 1 \quad P$. aeruginosa supernatant was mixed with $50 \mu 1$ MRSA culture, and which subsequently treated by Japonicin2LF at the same concentrations as MIC assay. The OD value was determined by the plate reader after $24 \mathrm{~h}$ incubation.

2.9 Stability of Japonicin-2LF in the presence of $P$. aeruginosa supernatant or human elastase

Japonicin-2LF $(50 \mu \mathrm{M})$ was incubated with $P$. aeruginosa supernatant or human neutrophil elastase (Merck, UK). Elastase was prepared at a peptide to enzyme ratio of 630:1 in $100 \mathrm{mM}$ Tris- $\mathrm{HCl}$ buffer containing $1 \% \mathrm{KCl}, \mathrm{pH}$ 7.6. At different time intervals $(0,15,30,60,120$ and $240 \mathrm{~min}$ ), $40 \mu \mathrm{l}$ of aliquots were withdrawn and mixed with $40 \mu 1$ of $0.1 \%$ TFA to stop the enzymatic reaction. The mixtures and Japonicin-2LF standards were analysed by LCQ coupled with a C18 column (Luna C18(2), $150 \times 2 \mathrm{~mm}, 5 \mu$; Phenomenex, UK). Samples were eluted at the flow rate of $0.2 \mathrm{ml} / \mathrm{min}$ by linear gradient elution $(0 \%$ to $95 \%$ solvent $\mathrm{B}$; solvent $\mathrm{A}: 0.1 \%$ TFA, solvent B: 95\% ACN/ 0.1\% TFA) in 25 min.

\subsection{Determination of Minimal Biofilm Inhibitory Concentration (MBIC) and Minimal Biofilm Eradication Concentration (MBEC)}

MBIC and MBEC assays were performed as previously described [22] with minor modifications. For MBIC assay, a suspension of broth-diluted bacteria culture $\left(5 \times 10^{5} \mathrm{CFU} / \mathrm{ml}\right)$ was incubated with the peptide solutions at $37^{\circ} \mathrm{C}$ for 24 hours. For MBEC assay, $100 \mu \mathrm{l}$ inoculum culture was seeded to a 96 -well-flat-bottom plate and incubated at $37^{\circ} \mathrm{C}$ for 48 hours to obtain the mature biofilm. Afterwards, the plate was washed by sterile phosphate buffered 
saline (PBS; Sigma-Aldrich, UK) twice and treated with a series peptide solution at $37^{\circ} \mathrm{C}$ for $24 \mathrm{~h}$. Then, all the plates were washed with PBS and stained by $100 \mu 10.1 \%$ crystal violet solution (Sigma-Aldrich, UK), and further dissolved by $30 \%$ acetic acid (Sigma-Aldrich, UK). The absorbance of each well was recorded by Synergy HT plate reader (Biotech, USA) at $595 \mathrm{~nm}$.

\subsection{MRSA Biofilm Disruption Assay}

MRSA biofilms were prepared in 96-well plates as previously described in MBEC assay. After washing by sterile PBS, biofilms were treated with different concentrations of japonicin-2LF at $37^{\circ} \mathrm{C}$ for $20 \mathrm{~h}$. Then, the plates were washed with PBS to remove all planktonic cells. $100 \mu \mathrm{l}$ PBS was added to the well and sonicated for $30 \mathrm{~min}$ at room temperature. The suspension was serially diluted in PBS and plated on MHA plates. The bacteria were counted after a $20 \mathrm{~h}$ incubation at $37^{\circ} \mathrm{C}$. PBS and $50 \mu \mathrm{M}$ vancomycin were employed as negative and positive control respectively.

\subsection{Membrane Permeability Assay}

The SYTOX green staining assay was performed as previously described [22]. The DAPI/PI staining process was achieved as described previously with proper modification [23, 24]. Briefly, peptide concentrations of MIC, $2 \times \mathrm{MIC}$ and $4 \times \mathrm{MIC}$ were mixed with bacteria suspension. The SYTOX green uptake was monitored by Synergy HT plate reader at excitation/emission: $485 / 528 \mathrm{~nm}$. Furthermore, the bacteria treated with japonicin-2LF were collected by centrifugation at $4^{\circ} \mathrm{C}$, followed by propidium iodide (PI; Sigma-Aldrich, UK) (5 $\mu \mathrm{g} / \mathrm{ml}$ ) staining for 15 minutes. Unbound PI was washed away by PBS, and the cells were stained with 4', 6-diamidino-2-phenylindole dihydrochloride (DAPI; Sigma-Aldrich, UK) (10 $\mu \mathrm{g} / \mathrm{ml}$ ) for another 15 minutes. The stained bacteria were observed by Leica DMi8 fluorescence microscopy (Leica, Germany). 


\subsection{Haemolysis Assay}

Peptide concentrations from $512 \mu \mathrm{M}$ to $1 \mu \mathrm{M}$ in 2 -fold dilution were mixed with $2 \%$ horse erythrocytes suspension, which was prepared from fresh defibrinated horse blood (TCS Biosciences, UK) as described in the previous study [18].

\subsection{Lactate Dehydrogenase (LDH) Cytotoxicity and MTT Assay}

The cytotoxicity assay was performed using Pierce ${ }^{\mathrm{TM}}$ LDH cytotoxicity assay kit (Thermo Fisher Scientific, UK). The MTT assay was performed with typical method described as pervious study [25]. The human lung epithelial cancer cell line, NCl-H23, $\left(\right.$ ATCC $^{\circledR}$ CRL$5800^{\mathrm{TM}}$ ) were treated with japonicin-2LF at concentrations from $128 \mu \mathrm{M}$ to $1 \mu \mathrm{M}$. The release of LDH was determined by Synergy HT plate reader $(490 \mathrm{~nm})$ after a $6 \mathrm{~h}$ incubation at $37^{\circ} \mathrm{C}$. For MTT assay, the formazan was dissolved by DMSO and detected at $540 \mathrm{~nm}$ using the plate reader.

\subsection{Assessing Efficacy of Japonicin-2LF against Different MRSA Strains in vivo}

This infection model employed wax moth larva (Galleria mellonella) as the previous study with minor modifications [26]. The larvae (Livefood UK Ltd, Rooks Bridge, UK) were selected between 225 to $275 \mathrm{mg}$ and were inoculated with $5 \mu 1$ MRSA bacteria suspension in PBS $\left(10^{8}\right.$ $\mathrm{CFU} / \mathrm{ml}$ ). All the infected larvae were confirmed to be alive at $1 \mathrm{~h}$ post-inoculation, followed by first treatment doses of $20 \mathrm{mg} / \mathrm{kg}$ vancomycin (positive control group), $25 \mathrm{mg} / \mathrm{kg}$ japonicin2LF (sample group) and $50 \mathrm{mg} / \mathrm{kg}$ japonicin-2LF (sample group). The negative control and positive control were injected $5 \mu \mathrm{l}$ of PBS and $20 \mathrm{mg} / \mathrm{kg}$ vancomycin (Sigma-Aldrich, UK), respectively. Repeat treatment doses of vancomycin and japonicin-2LF were given at 12 and $24 \mathrm{~h}$. Each group contained 10 larvae and was repeated three times. All larvae were inspected every $24 \mathrm{~h}$ for 5 days.

\subsection{Statistical Analyses}


Obtained data were analysed to obtain the mean and standard error of the mean. The statistical analyses of survival rate were performed using log-rank test and One-way ANOVA indicated by ns (none significant difference), $*(\mathrm{p}<0.05), * *(\mathrm{p}<0.01)$ and $* * *(\mathrm{p}<0.001)$. All the statistical analysis were performed by GraphPad Prism 6 software.

\subsection{Ethics}

The skin secretion acquisition procedure was performed under UK Animal (Scientific Procedures) Act 1986, project licence PPL 2694 as issued by the Department of Health, Social Services and Public Safety, Northern Ireland. All procedures were vetted by the IACUC of Queen's University Belfast and approved on March 1, 2011.

\section{Results}

\subsection{Identification and Characterisation of Japonicin-2LF from the Skin Secretion}

The prepropeptide encoding cDNA was successfully sequenced, and the translated open reading frame consists of 67 amino-acid residues (Figure S1a). The LC-MS analysis confirmed the primary structure of mature peptide as well as its presence in the skin secretion (Figure S1b $\&$ c). The topological domains were differentiated by a signal peptide terminated by a cysteine residue, a predicted putative mature peptide with 20 amino-acid residues followed by a typical di-basic peptide convertase processing site (-KR-), and an acidic acidic-rich spacer peptide in between.

The alignment exhibits a high degree of similarity between japonicin-2LF and Japonicin2OM1, which has one extra Asn in the conserved "Rana-box" segment (Figure 1). Accordingly, we named this novel peptide following japonicin-2OM1, as japonicin-2LF. 
The synthetic replicates were purified by RP-HPLC and analysed by MALDI-TOF (Figure S2).The CD analysis reveals that japonicin-2LF form a random coil structure in the aqueous environment, while it forms an $\alpha$-helical structure in the membrane-mimic solutions (Figure 2).

\subsection{Antimicrobial Activity of Japonicin-2LF}

Japonicin-2LF exhibited potent antimicrobial activity against Gram-positive bacteria and the yeast fungi, while showed no inhibitory activity against Gram-negative stains except E. coli (Table 1). The antimicrobial potency against three MRSA strains was unchanged after the induction of resistance. Additionally, we examined the influence of $P$. aeruginosa supernatant on the antimicrobial sensitivity of MRSA to Japonicin-2LF. In the presence of P. aeruginosa supernatant, the antimicrobial activity of Japonicin-2LF against MRSA decreased 8-fold (Table 2).

\subsection{Stability of Japonicin-2LF}

The amount of Japonicin-2LF in the presence of $P$. aeruginosa supernatant or human neutrophil elastase was quantitated at different time intervals, applying to an established calibration curve (Figure S3), which showed that Japonicin-2LF was instable in both conditions (Figure 3). Interestingly, the amount of Japonicin-2LF considerably decreased once it mixed with P. aeruginosa supernatant ( $0 \mathrm{~min})$, without detection of cleaved fragment by MS analysis (data not shown).

\subsection{Antibiofilm Activity of Japonicin-2LF}

Additionally, Japonicin-2LF more potently inhibited and eradicated bacteria biofilms of $S$. aureus and MRSA than which of E. coli (Table 3). The disruption assay further displayed that japonicin-2LF eradicated all sessile bacteria in the MRSA biofilms at the concentration of respective MBECs (Figure 4). 


\subsection{Membrane Permeability Assay}

Japonicin-2LF compromised the integrity of the membranes of three standard microorganism

cell types, S. aureus, E. coli and C. albicans. Although it induced around 100\% permeability of cell membranes at 4-fold of respective MICs, japonicin-2LF exhibited more potent membrane disruptive effect on S. aureus at 1-fold MICs than the others (Figure 5). The DAPI/PI staining confirmed that japonicin-2LF resulted in a high degree of membrane permeabilisation at the concentration of 4-fold MICs against the three microorganisms, while it damaged the cell membrane of S. aureus at 1-fold MIC only (Figure 6).

\subsection{Haemolytic, MTT and Cytotoxic Activity}

Japonicin-2LF exhibited more than $80 \%$ haemolysis from the concentration of $64 \mu \mathrm{M}$, while the effect was below $25 \%$ at lower concentrations (Figure 7a). As japonicin-2LF demonstrated antimicrobial activity against the strains from CF patients, we investigated the cytotoxicity on lung cells. Both assays show that japonicin-2LF induce cytotoxicity from the concentration of $64 \mu \mathrm{M}$ (Figure 7b), which is similar to its haemolytic activity.

\subsection{Treatment of MRSA-infected Larvae with Japonicin-2LF}

The mortality of three MRSA strains infected larvae was significantly decreased by the treatment of $50 \mathrm{mg} / \mathrm{kg}$ of japonicin-2LF. The lower dose, $25 \mathrm{mg} / \mathrm{kg}$, resulted in the similar survival rate to $50 \mathrm{mg} / \mathrm{kg}$ in both MRSA NCTC 12493 and MRSA B038 V1S1 A (Figure 8). In addition, both doses did not decrease the survival rate of uninfected larvae, indicating japonicin-2LF showed neglectable cytotoxicity in larvae (Figure S4). 


\section{Discussion}

AMPs have demonstrated remarkable antimicrobial effects and appeared as potential antibiotic agents for treating emerging antibiotic resistance because most of them exert the function through membrane permeabilisation [27]. Therefore, it was unsurprising that japonicin-2LF inhibited both wild-type bacteria strains as well as the antibiotic-resistance strains, as they have no considerable difference between their cell membranes, where the antimicrobial peptides are commonly targeted [28]. So, the antimicrobial effects of AMPs might not be affected by the presence of resistant genes for conventional antibiotics [29]. We also demonstrated that the MRSA strains in this study did not generate resistance to japonicin-2LF after exposure to this peptide at sub-MIC for two weeks. However, the antimicrobial effects could be suppressed by the changes of cell wall structures of microorganisms. It was reported that the constitution of A- and B-band LPS of S. maltophilia and P. aeruginosa outer membrane could alter the hydrophobicity and charge of the cell surface $[30,31]$. These changes can directly affect the interaction between AMPs and bacterial cell membranes, which could explain the reason that japonicin-2LF was ineffective against $P$. aeruginosa. Besides, the slight difference in the amino acid sequence of AMPs can alter the effect distinctively. As the alignment shows, japonicin2LF displays similar amino acid constitution to japonicin-2OM1 with only one Asn less, while showing more potent inhibition against bacteria comparing to previous data [32], which may be caused by the changes to amphipathicity of AMPs that influences the ability to disrupt cell membrane.

In expectation, japonicin-2LF permeabilised the cell membrane straightforward and rapidly, especially towards Gram-positive bacteria cells. As the DAPI/PI staining assay indicated, the membrane permeabilisation was initiated once the peptide was mixed with cell suspensions. japonicin-2LF easily passed through the hydrophilic peptidoglycan layer and disrupted the intact membrane of S. aureus, whereas the effect was weakened on E. coli due to that the helical 
peptide usually has higher affinity to LPS in the outer membrane [33], which may prevent the translocation to the cell membrane. Interestingly, the MBIC and MBEC of japonicin-2LF against Staphylococcus strains are the same as the respective MIC and MBC. We assumed that the inhibition of biofilm formation might be related to the growth inhibition of planktonic bacteria and surface colonisation of initial biofilm formation [34]. Similarly, japonicin-2LF exhibited the detergent-like function to disintegrate the biofilm as well as killing all the bacteria inside. Therefore, japonicin-2LF can effectively eradicate both planktonic and sessile pathogens rapidly, which could be applied in both acute and chronic infections.

The strong mucus phenotype of CF provides a pleasant environment for the bacteria, and the chronic infection by them up-regulates the mucin gene expression via inflammation pathway [35]. Whereas, Japonicin-2LF can perforate cell membrane and disintegrate the biofilm directly on different strains since membrane-disruption AMPs meet these challenge and are considered to be possible alternative substances to antibiotics facing chronic infection like CF [36]. As another predominate bacteria in CF, $P$. aeruginosa was reported to protect $S$. aureus from antibiotics treatment that effects of vancomycin were significantly eliminated against S. aureus by the compounds in P. aeruginosa supernatant [21]. Therefore, we investigated the influence of the supernatant on the antimicrobial activity of japonicin-2LF against MRSAs, and it turned out that there is an 8 -fold decrease in such condition. Although japonicin-2LF was instable in the presence of both P. aeruginosa supernatant and human elastase that resulting the deficiency of anti-MRSA effects, we noticed that the amount of peptide decreased significantly in the $P$. aeruginosa supernatant at $0 \mathrm{~min}$, without producing any cleaved peptide fragments (data not shown). It suggested that japonicin-2LF may bind to the hydrophobic/amphipathic compounds (e.g. quorum-sensing molecules) in the supernatant non-specifically, decreasing the concentration of free japonicin-2LF. Whilst, further investigations on identifying peptide- 
binding molecules in the $P$. aeruginosa supernatant can help to clarify the deficiency of antimicrobial activity.

Wax moth larva (G. mellonella) infection model has been used to assess the efficacy of antiStaphylococcus agents [37]. Japonicin-2LF significantly decreased the mortality of infected larvae, but the efficacy against three MRSA stains was different. Notably, more than $50 \%$ of infected larvae survived after 5 days with MRSA B038 at both doses, while only $50 \mathrm{mg} / \mathrm{kg}$ increased the survival rate of the larvae infected by MRSA B042. In contrast, the virulence of three stains in 5 days are similar, but the infection of MRSA B038 resulted in the death of the larvae in the first $12 \mathrm{~h}$. The reason remains unclear, but we assume that the infection of MRSA B038 might stimulate a different immune response and then japonicin-2LF might be able to treat the MRSA infection synergistically in this situation.

Cationic antimicrobial peptide usually exhibited cytotoxicity on cancer cells because cancer cells contain more negative charges on the cell surface than which of normal cells, that improves the electrostatic interaction for peptide attachment [25]. Japonicin-2LF could induce low degree of cytotoxicity on normal cells and recognise the negatively-charged bacteria cells in the G. mellonella larvae. It is also proved by that there was no death of larvae caused by injection of two doses of japonicin-2LF.

Antibiotics remain debatable and controversial due to the emerging resistant strains. However, we believe that the resistant strains, like MRSA, are hard to generate resistance to japonicin2LF because of the unique membrane-disruption mechanism. With the help of japonicin-2LF, the therapy may be improved when treating MRSA infection in CF patients, and further implied that japonicin-2LF could be a promising candidate in MRSA related clinical perspective. 


\section{Acknowledgements}

The clinical isolates from CF patients are the courtesy of Prof. Michael Tunney from CF and airways research group in Queen's University Belfast, UK.

\section{Funding}

No funding.

\section{Supplementary Flies}

Figure S1, S2, S3 and S4 were presented in the supplementary material.

\section{References}

[1] J.R. Yankaskas, B.C. Marshall, B. Sufian, R.H. Simon, D. Rodman, Cystic fibrosis adult care: consensus conference report, Chest, 125 (2004) 1S-39S.

[2] J.Y. Ang, N. Abdel-Haq, F. Zhu, A.K. Thabit, D.P. Nicolau, M.J. Satlin, D. van Duin, Multidrug-Resistant Pseudomonas aeruginosa Infection in a Child with Cystic Fibrosis, Antimicrob Agents Chemother, 60 (2016) 5627-5630.

[3] G.P. Stoyanova, T.V. Strateva, S.T. Atanasova, D.S. Miteva, V.E. Papochieva, P.I. Perenovska, Pulmonary exacerbation due to colistin-resistant Stenotrophomonas maltophilia in a Bulgarian cystic fibrosis patient, Folia Med (Plovdiv), 58 (2016) 136-140.

[4] O. Denis, C. Nonhoff, B. Byl, C. Knoop, S. Bobin-Dubreux, M.J. Struelens, Emergence of vancomycin-intermediate Staphylococcus aureus in a Belgian hospital: microbiological and clinical features, J Antimicrob Chemother, 50 (2002) 383-391.

[5] S.C. Bell, P.A. Flume, Treatment decisions for MRSA in patients with cystic fibrosis (CF): when is enough, enough?, Thorax, 72 (2017) 297-299.

[6] D.K. Lo, M.N. Hurley, M.S. Muhlebach, A.R. Smyth, Interventions for the eradication of meticillin-resistant Staphylococcus aureus (MRSA) in people with cystic fibrosis, Cochrane Database Syst Rev, (2015) CD009650.

[7] E.C. Dasenbrook, W. Checkley, C.A. Merlo, M.W. Konstan, N. Lechtzin, M.P. Boyle, Association between respiratory tract methicillin-resistant Staphylococcus aureus and survival in cystic fibrosis, JAMA, 303 (2010) 2386-2392.

[8] Anon., Cystic Fibrosis Foundation Patient Registry 2015 Annual Data Report, in, Cystic Fibrosis Foundation, Bethesda, Maryland, 2016.

[9] M.T. Jennings, E.C. Dasenbrook, N. Lechtzin, M.P. Boyle, C.A. Merlo, Risk factors for persistent methicillin-resistant Staphylococcus aureus infection in cystic fibrosis, J Cyst Fibros, 16 (2017) 681-686.

[10] J.E. Payne, A.V. Dubois, R.J. Ingram, S. Weldon, C.C. Taggart, J.S. Elborn, M.M. Tunney, Activity of innate antimicrobial peptides and ivacaftor against clinical cystic fibrosis respiratory pathogens, Int J Antimicrob Agents, 50 (2017) 427-435. 
[11] N. Molchanova, P.R. Hansen, H. Franzyk, Advances in Development of Antimicrobial Peptidomimetics as Potential Drugs, Molecules, 22 (2017).

[12] M. AlMatar, E.A. Makky, G. Yakici, I. Var, B. Kayar, F. Koksal, Antimicrobial peptides as an alternative to anti-tuberculosis drugs, Pharmacol Res, (2017).

[13] J.M. Pantic, I.P. Jovanovic, G.D. Radosavljevic, N.N. Arsenijevic, J.M. Conlon, M.L. Lukic, The Potential of Frog Skin-Derived Peptides for Development into TherapeuticallyValuable Immunomodulatory Agents, Molecules, 22 (2017).

[14] J.M. Conlon, M. Mechkarska, Y.H. Abdel-Wahab, P.R. Flatt, Peptides from frog skin with potential for development into agents for Type 2 diabetes therapy, Peptides, 100 (2018) 275281.

[15] B. Casciaro, M.R. Loffredo, V. Luca, W. Verrusio, M. Cacciafesta, M.L. Mangoni, Esculentin-1a Derived Antipseudomonal Peptides: Limited Induction of Resistance and Synergy with Aztreonam, Protein Pept Lett, (2018).

[16] B. Casciaro, F. Cappiello, M. Cacciafesta, M.L. Mangoni, Promising Approaches to Optimize the Biological Properties of the Antimicrobial Peptide Esculentin-1a(1-21)NH2: Amino Acids Substitution and Conjugation to Nanoparticles, Front Chem, 5 (2017) 26.

[17] M.J. Tyler, D.J. Stone, J.H. Bowie, A novel method for the release and collection of dermal, glandular secretions from the skin of frogs, J Pharmacol Toxicol Methods, 28 (1992) 199-200.

[18] Y. Gao, D. Wu, L. Wang, C. Lin, C. Ma, X. Xi, M. Zhou, J. Duan, O.R.P. Bininda-Emonds, T. Chen, C. Shaw, Targeted Modification of a Novel Amphibian Antimicrobial Peptide from Phyllomedusa tarsius to Enhance Its Activity against MRSA and Microbial Biofilm, Front Microbiol, 8 (2017) 628.

[19] D. Wu, Y. Gao, L. Wang, X. Xi, Y. Wu, M. Zhou, Y. Zhang, C. Ma, T. Chen, C. Shaw, A Combined Molecular Cloning and Mass Spectrometric Method to Identify, Characterize, and Design Frenatin Peptides from the Skin Secretion of Litoria infrafrenata, Molecules, 21 (2016). [20] D. Wu, Y. Gao, Y. Tan, Y. Liu, L. Wang, M. Zhou, X. Xi, C. Ma, O.R.P. Bininda-Emonds, T. Chen, C. Shaw, Discovery of Distinctin-Like-Peptide-PH (DLP-PH) From the Skin Secretion of Phyllomedusa hypochondrialis, a Prototype of a Novel Family of Antimicrobial Peptide, Front Microbiol, 9 (2018) 541.

[21] G. Orazi, G.A. O'Toole, Pseudomonas aeruginosa Alters Staphylococcus aureus Sensitivity to Vancomycin in a Biofilm Model of Cystic Fibrosis Infection, MBio, 8 (2017).

[22] L. Huang, D. Chen, L. Wang, C. Lin, C. Ma, X. Xi, T. Chen, C. Shaw, M. Zhou, Dermaseptin-PH: A Novel Peptide with Antimicrobial and Anticancer Activities from the Skin Secretion of the South American Orange-Legged Leaf Frog, Pithecopus (Phyllomedusa) hypochondrialis, Molecules, 22 (2017).

[23] Y. Li, C. Smith, H. Wu, S. Padhee, N. Manoj, J. Cardiello, Q. Qiao, C. Cao, H. Yin, J. Cai, Lipidated cyclic gamma-AApeptides display both antimicrobial and anti-inflammatory activity, ACS Chem Biol, 9 (2014) 211-217.

[24] N.A. Wani, G. Singh, S. Shankar, A. Sharma, M. Katoch, R. Rai, Short hybrid peptides incorporating beta- and gamma-amino acids as antimicrobial agents, Peptides, 97 (2017) 4653.

[25] J. Liu, Q. Wu, L. Li, X. Xi, D. Wu, M. Zhou, T. Chen, C. Shaw, L. Wang, Discovery of Phylloseptins that Defense against Gram-Positive Bacteria and Inhibit the Proliferation of the Non-Small Cell Lung Cancer Cell Line, from the Skin Secretions of Phyllomedusa Frogs, Molecules, 22 (2017).

[26] A.P. Desbois, P.J. Coote, Wax moth larva (Galleria mellonella): an in vivo model for assessing the efficacy of antistaphylococcal agents, J Antimicrob Chemother, 66 (2011) 17851790. 
[27] M. Jarva, T.K. Phan, F.T. Lay, S. Caria, M. Kvansakul, M.D. Hulett, Human beta-defensin 2 kills Candida albicans through phosphatidylinositol 4,5-bisphosphate-mediated membrane permeabilization, Sci Adv, 4 (2018) eaat0979.

[28] F.G. Avci, B.S. Akbulut, E. Ozkirimli, Membrane Active Peptides and Their Biophysical Characterization, Biomolecules, 8 (2018).

[29] D.I. Andersson, D. Hughes, J.Z. Kubicek-Sutherland, Mechanisms and consequences of bacterial resistance to antimicrobial peptides, Drug Resist Updat, 26 (2016) 43-57.

[30] S.A. Makin, T.J. Beveridge, The influence of A-band and B-band lipopolysaccharide on the surface characteristics and adhesion of Pseudomonas aeruginosa to surfaces, Microbiology, 142 ( Pt 2) (1996) 299-307.

[31] J.S. Brooke, Stenotrophomonas maltophilia: an emerging global opportunistic pathogen, Clin Microbiol Rev, 25 (2012) 2-41.

[32] Y. Hu, S. Xu, Y. Hu, C. Guo, H. Meng, J. Li, J. Liu, H. Wang, Diverse families of antimicrobial peptides isolated from skin secretions of three species of East Asian frogs, Babina daunchina, Babina adenopleura, and Rana omeimontis (Ranidae), Zoolog Sci, 31 (2014) 438444.

[33] Y. Sun, D. Shang, Inhibitory Effects of Antimicrobial Peptides on LipopolysaccharideInduced Inflammation, Mediators Inflamm, 2015 (2015) 167572.

[34] H.Y. Wang, J.W. Cheng, H.Y. Yu, L. Lin, Y.H. Chih, Y.P. Pan, Efficacy of a novel antimicrobial peptide against periodontal pathogens in both planktonic and polymicrobial biofilm states, Acta Biomater, 25 (2015) 150-161.

[35] S.M. Kreda, C.W. Davis, M.C. Rose, CFTR, mucins, and mucus obstruction in cystic fibrosis, Cold Spring Harb Perspect Med, 2 (2012) a009589.

[36] N.Y. Yount, M.R. Yeaman, Emerging themes and therapeutic prospects for anti-infective peptides, Annu Rev Pharmacol Toxicol, 52 (2012) 337-360.

[37] A. Coughlan, K. Scanlon, B.P. Mahon, M.R. Towler, Zinc and silver glass polyalkenoate cements: an evaluation of their antibacterial nature, Biomed Mater Eng, 20 (2010) 99-106. 


\section{Legends to Figures}

Figure 1. Alignments of translated open reading frame prepropeptide amino acid sequences of japonicin-2LF and top NCBI BLAST analytes. The accession numbers are showed before the sequences. The identical amino acids are yellow highlighted. The mature peptide sequence of japonicin-2LF was underlined and the propeptide convertase processing site was indicated by arrows.

Figure 2. CD spectrum of japonicin-2LF $(100 \mu \mathrm{M})$ in $10 \mathrm{mM}$ in $10 \mathrm{mM} \mathrm{NH} 4 \mathrm{Ac}, 50 / 50(\mathrm{v} / \mathrm{v})$ TFE/10 mM NH $4 A c$, and $50 \mathrm{mM} \mathrm{SDS} / 10 \mathrm{mM} \mathrm{NH}_{4} \mathrm{Ac}$.

Figure 3. The stability of japonicin-2LF $(50 \mu \mathrm{M})$ in the presence of $P$. aeruginosa supernatant or human neutrophil elastase.

Figure 4. The colony counts of MRSA stains, NCTC 12493, B038 V1S1 A and B042 V2E1 A, after disrupting the respective biofilms. PBS and $50 \mu \mathrm{M}$ vancomycin were employed as negative control $(\mathrm{N})$ and positive control $(\mathrm{P})$, respectively. Error bars indicate standard deviation (SEM) of five replicates.

Figure 5. The SYTOX green uptake effect of S. aureus, E. coli and C. albicans in the treatment of 1-fold, 2-fold and 4-fold MICs. The 100\% permeability of cell membrane was conducted using the same amount of microorganism cells treated by $70 \%$ isopropanol $(\mathrm{P})$. Error bars indicate standard error of the mean (SEM) of five replicates.

Figure 6. Fluorescence graphs and merged graphs of DAPI/PI staining of a) S. aureus, b) E. coli, and c) C. albicans treated with 1-fold and 4-fold MICs of japonicin-2LF.

Figure 7. Toxicity of japonicin-2LF. a) Haemolysis of japonicin-2LF on horse erythrocytes. b) Release of LDH from NCl-H23 cells and the corresponding cell viability in the treatment of japonicin-2LF. The percentage was calculated based on the effect induced by the positive 
control $(\mathrm{P}), 1 \%$ Triton $\mathrm{X}-100$. PBS was used as negative control $(\mathrm{N})$. Error bars indicate standard error of the mean (SEM) of three replicates.

Figure 8. The mortality of $G$. mellonella larvae ( $\mathrm{n}=30$ for each group) infected with MRSA stains, including a) NCTC 12493, b) B038 V1S1 A and c) B042 V2E1 A. The infected larvae were treated with $5 \mu 120 \mathrm{mg} / \mathrm{kg}$ vancomycin, $25 \mathrm{mg} / \mathrm{kg}$ japonicin-2LF and $50 \mathrm{mg} / \mathrm{kg}$ japonicin2LF, respectively. Treatments were administered at 0,12 and $24 \mathrm{~h}$, as the arrows indicated. The statistical analyses were performed by Mantel-Cox test and the statistical significance was indicated as ns (none significant difference), $*(\mathrm{p}<0.05)$, and $* *(\mathrm{p}<0.01)$. 


\section{Legends to Tables}

Table 1. The MICs, MBCs of japonicin-2LF and MICs of positive controls against both reference and $\mathrm{CF}$ isolated strains.

Table 2. The MICs of japonicin-2LF against the three MRSA stains in the absence and presence of $P$. aeruginosa supernatant.

Table 3. The MBICs and MBECs of japonicin-2LF against the biofilm of S. aureus, E. coli and MRSA stains. 